\title{
Development of a nanoparticle-assisted PCR assay for detection of bovine respiratory syncytial virus
}

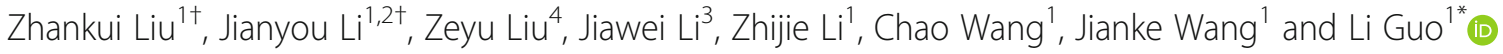

\begin{abstract}
Background: Bovine respiratory syncytial virus (BRSV) is a common pathogen causing respiratory disease in cattle and a significant contributor to the bovine respiratory disease (BRD) complex. BRSV is widely distributed around the world, causing severe economic losses. This study we established a new molecular detection method of BRSV pathogen NanoPCR attributed to the combination of nano-particles in traditional PCR (Polymerase chain reaction) technology.

Results: In this study, the BRSV NanoPCR assay was developed, and its specificity and sensitivity were investigated. The results showed that no cross-reactivity was observed for the NanoPCR assay for related viruses, including the infectious bovine rhinotracheitis virus (IBRV), bovine viral diarrhea virus (BVDV), and bovine parainfluenza virus type 3 (BPIV3), and the assay was more sensitive than the conventional PCR assay, with a detection limit of $1.43 \times 10^{2}$ copies recombinant plasmids per reaction, compared with $1.43 \times 10^{3}$ copies for conventional PCR analysis. Moreover, thirty-nine clinical bovine samples collected from two provinces in North-Eastern China, $46.15 \%$ were determined BRSV positive by our NanoPCR assay, compared with 23.07\% for conventional PCR.
\end{abstract}

Conclusions: This is the first report to demonstrate the application of a NanoPCR assay for the detection of BRSV. The sensitive and specific NanoPCR assay developed in this study can be applied widely in clinical diagnosis and field surveillance of BRSV infection.

Keywords: Nanoparticle-assisted PCR assay, Bovine respiratory syncytial virus, Detection

\section{Background}

Bovine respiratory syncytial virus (BRSV) [1] is a significant cause of respiratory disease and a major contributor to the bovine respiratory disease (BRD) complex [2]. Nanoparticle-assisted polymerase chain reaction (NanoPCR) is a recently developed technique for the rapid detection of bacterial and viral nucleic acid. In the 2-6 month-old calves, the incidence of BRSV infection is high, and the mortality rate is low, secondary bacterial infection, the mortality rate can reach more than $20 \%$ [3], the symptoms of re-infection is not apparent after healing the infected calves, the virus can also isolate on cattle without clinical symptoms. Temperature

\footnotetext{
*Correspondence: piaogl110@163.com

Zhankui Liu and Jianyou Li are co-first authors.

${ }^{1}$ Institute of Special Animal and Plant Sciences, Chinese Academy of

Agricultural Sciences, Changchun 130112, China

Full list of author information is available at the end of the article
}

drop or long-distance transport and other stress conditions can also cause outbreaks [4].

In most cases, BRSV can exist for a long time in a herd [5]. However, the specific mechanism is not precise and needs to be studied systematically. The current diagnostic methods for BRSV are primarily enzyme-linked immunosorbent assay (ELISA) and real-time PCR (RT-PCR) [6-8]. Due to the low and unstable replication of the virus, the sensitivity of the previously-mentioned methods is insufficient and often leads to false negative results. Thus, proper diagnosis of the disease is imperative to prevent misdiagnose of the disease and treatment can be given to affected herd. There is still a lack of systematic research on BRSV even though there is a rapid development of the cattle industry in China. Therefore, it is urgent to establish a molecular detection method for BRSV that is efficient, rapid, specific and reproducible. 
In 2005, $\mathrm{Li}$ et al. [9] reported that nanoparticles $(\mathrm{Au}$ nanoparticles, AuNPs) can be used as novel PCR additives to inhibit the production of nonspecific bands in the reamplification system, which can significantly improve nonspecific amplification, wide temperature range is useful, suggesting that nano-gold can produce similar single-stranded binding protein (single-stranded DNA binding protein, SSB) effect and improve the specificity of PCR. Then, $\mathrm{Li}$ et al. found that nano-gold can enhance the sensitivity and reaction rate of PCR. The excellent thermal conductivity of nano-gold is the basis for the optimization of nanoparticles. They believe that the role of nano-gold to improve the rapid rise/fall PCR system thermal conductivity, which facilitates the template and primer to be more efficiently matched, NanoPCR technology has also become a new type of PCR technology [10]. Compared with traditional PCR, NanoPCR can improve the sensitivity of PCR detection. Also, NanoPCR saves time more than conventional PCR.

Due to the low sensitivity and low efficiency of the existing molecular detection methods of bovine respiratory syncytial virus (BRSV), We hoping to establish a high sensitivity, simple, rapid and efficient method for detection of BRSV by using nano-gold and PCR molecular detection technology to realize the rapid diagnosis of $\mathrm{BRSV}$, which is of great significance to disease control.

\section{Results}

\section{Optimization of BRSV NanoPCR assay conditions}

The optimization of NanoPCR reaction was performed by using BRSV 391-2 strain. Optimized conditions included the optimal concentration of primers, optimal concentration, the diameter of gold nanoparticles, and optimal annealing temperature and time. Using optimized parameters, the NanoRCR amplified BRSV fragment was $600 \mathrm{bp}$ in size. The sequence analysis also showed high similarity (100\%) between the products obtained with the NanoPCR amplification of the $\mathrm{N}$ gene for BRSV (the objective sequences) and the reference sequence of BRSV. It was found that the band density was optimal at the $55^{\circ} \mathrm{C}$ annealing temperature, which was selected for subsequent studies (Fig. 1a). Using this annealing temperature, it was found that the band density was the highest when the gold nanoparticle volume and diameter of nanoparticle were $0.7 \mu \mathrm{L}$ (Fig. 1b), and 20 $\mathrm{nm}, 23 \mathrm{~nm}$ and $40 \mathrm{~nm}$ (Fig. 1c) respectively. In addition, when the annealing time of NanoPCR was reduced to 5 $\mathrm{s}$, the experiment is still valid (Fig. 1d), but the RT-PCR is not valid. This result provides the basis for the rapid diagnosis.

Based on the optimization results, an optimal $25 \mu \mathrm{L}$ reaction volume was established, containing $2.5 \mu \mathrm{L} 10 \times$ buffer, $2 \mu \mathrm{L}$ dNTP, $1.5 \mu \mathrm{L} \mathrm{Mg}^{2+}, 0.5 \mu \mathrm{L}$ Taq DNA polymerase (TAKARA), $0.7 \mu \mathrm{L}$ gold nanoparticles, $1.0 \mu \mathrm{L}$ of extracted DNA or standard plasmid, $0.5 \mu \mathrm{L}$ of each of forward and reverse primer $(10 \mu \mathrm{M})$ and $\mathrm{ddH}_{2} \mathrm{O}$ up to $25 \mu \mathrm{L}$. The reaction conditions were as follows: $94{ }^{\circ} \mathrm{C}$ for $5 \mathrm{~min}$ and 35 cycles of $94^{\circ} \mathrm{C}$ for $30 \mathrm{~s}, 57^{\circ} \mathrm{C}$ for $5 \mathrm{~s}$, and $72{ }^{\circ} \mathrm{C}$ for $30 \mathrm{~s}$, with a final extension for $5 \mathrm{~min}$ at $72{ }^{\circ} \mathrm{C}$.

\section{Specificity of the BRSV NanoPCR assay}

Agarose gel electrophoresis analysis showed that no cross-reactivity was observed for related viruses by NanoPCR and conventional PCR, including infectious bovine rhinotracheitis virus (IBRV), bovine viral diarrhea virus (BVDV), and bovine parainfluenza Virus Type 3 (BPIV3) (Fig. 2). The result indicated that the NanoPCR method for the detection of BRSV is specific.

\section{Sensitivity of the BRSV NanoPCR assay}

The sensitivity of BRSV NanoPCR reaction was determined. The detection limit of BRSV NanoPCR assay $\left(1.43 \times 10^{2}\right.$ copies $/ \mu \mathrm{L}$, Fig. $\left.3 \mathrm{~b}\right)$ was 10 -fold more sensitive than conventional assay $\left(1.43 \times 10^{3}\right.$ copies $/ \mu \mathrm{L}$, Fig. $\left.3 \mathrm{a}\right)$.

\section{Detection of BRSV in clinical samples}

BRSV NanoPCR and conventional PCR were used in clinical samples. Eight (20.5\%) of the thirty-nine samples tested by NanoPCR and conventional PCR were positive, and twenty-four (61.5\%) were negative by NanoPCR and conventional PCR. Seven samples (17.9\%) positive for NanoPCR were negative by conventional PCR, whereas no samples negative for NanoPCR were found to be positive by conventional PCR. Twelve of the fifteen samples tested positive for NanoPCR came from nasal swabs, while six of the eight positive results detected by conventional PCR came from nasal swabs. All the other positive samples came from feces. The NanoPCR random products of five positive sample were subjected subsequently to automated sequencing reactions. The sequence analysis showed high similarity (100\%) between the products obtained with the NanoPCR amplification and the reference sequence of BRSV. Clinical samples detection by BRSV NanoPCR were shown in Fig. 4.

\section{Discussion}

In 1970, Paccaud et al [11] first identified BRSV in Europe. In 1974, it was again identified in the United States $[12,13]$. It is still an important factor in BRD. The virus is transmitted through nasal secretions and may survive due to the heterogeneity of its genome and the low fidelity of replication. IHC (Immunohistochemistry) and RT-PCR are used to identify viral antigens and viral genome in field specimens easily [14]. The virus is unstable and it is often impossible to try to separate it from clinical samples in the laboratory. Due to rapid turnaround time, RT-PCR has become increasingly popular as a means of identifying BRSV in clinical cases 


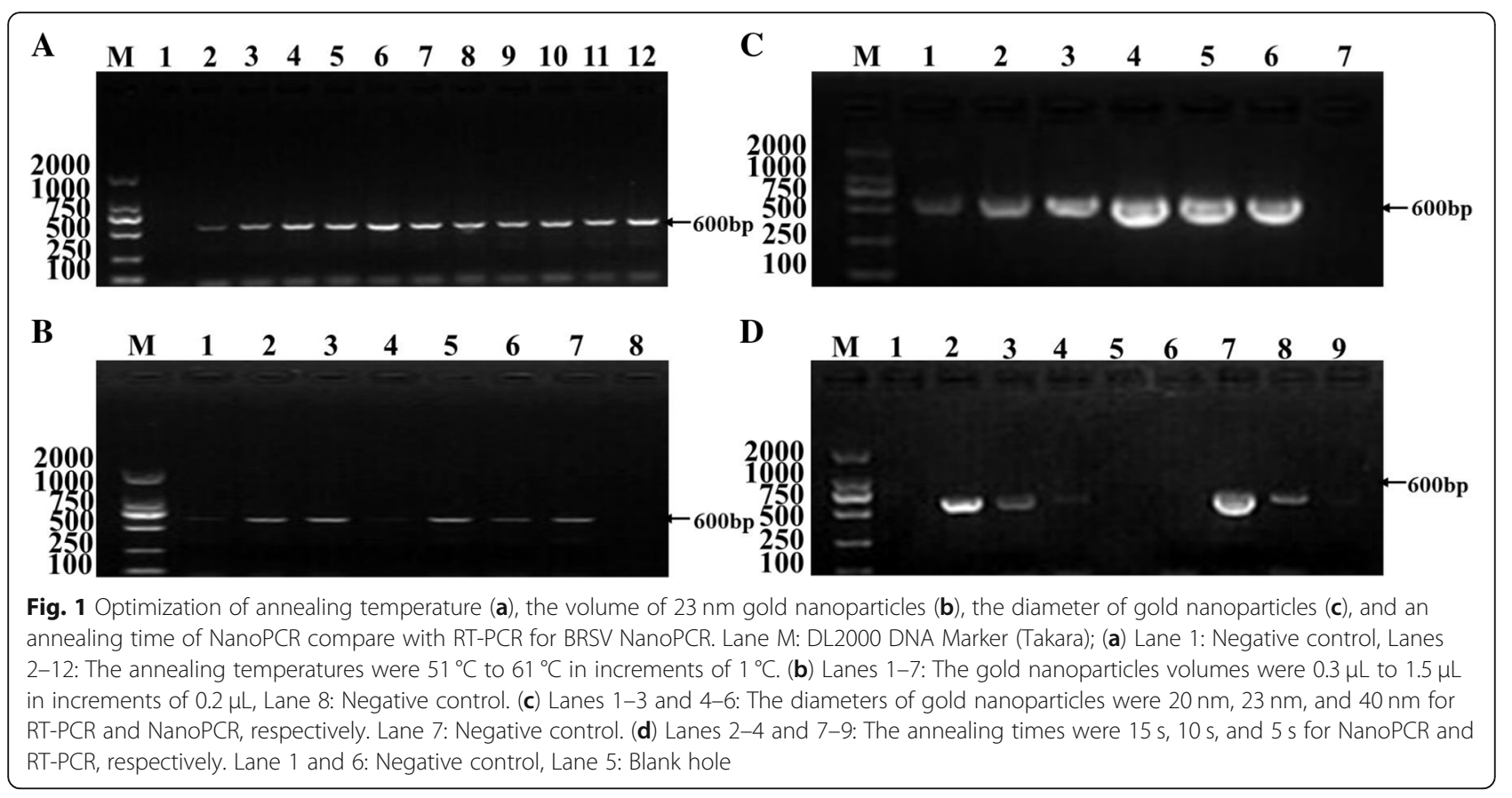

[14]. In 2005, $\mathrm{Li}$ et al. [9] showed an excellent optimization effect by adding gold nanoparticles with a diameter of $10 \mathrm{~nm}$ and a concentration of $0.4 \mathrm{~nm}$ to the PCR system. It is pointed out that the concentration of colloidal gold plays a crucial role in the specificity of PCR. When the concentration of colloidal gold is within the appropriate range $(0.2-0.8 \mathrm{~nm})$, the number of nonspecific bands is less and less. The target band is gradually enhanced, and a single bright target band can be obtained. However, when the gold nanoparticles were in excess, the phenomenon of inhibiting the amplification was shown [15].

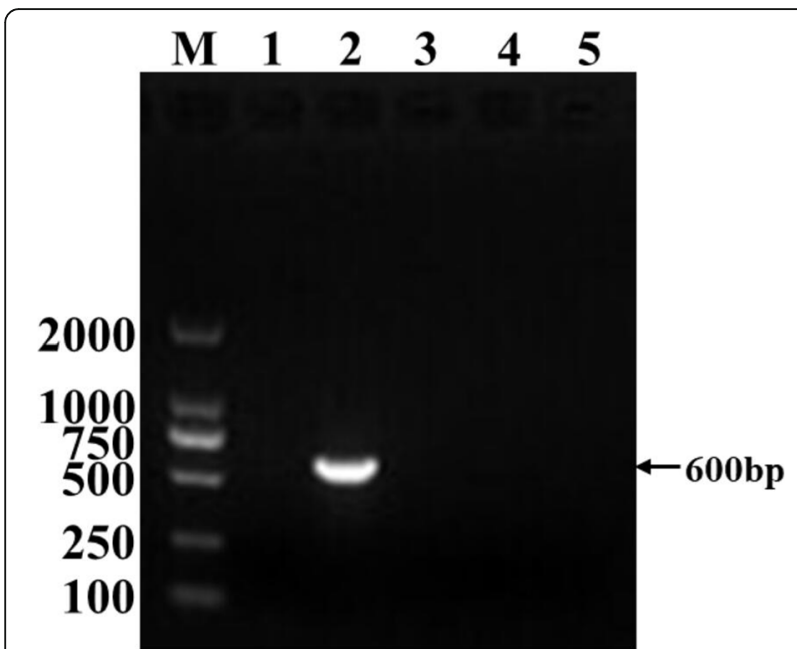

Fig. 2 Specificity of the BRSV NanoPCR assay. Lane M: DL2000 DNA Marker (Takara); Lane 1: Negative control; Lane 2-5: The standard positive plasmids of BRSV, IBRV, BIPV3, and BVDV, respectively
There are many methods to detect BRSV, including RT-PCR, fluorescence quantitative PCR, ELISA and immunofluorescence antibody detection [16-19]. However, due to antibody reactions, these serological techniques do not distinguish between vaccines and natural infections of wild-type viruses. Besides, although conventional PCR has been used to identify BRSV infection [7], it is time-consuming and insensitive and is not suitable for detecting low viral load in clinical samples. Besides, although LAMP (Loop-mediated isothermal amplification) detects simple [8], it is very vulnerable to contamination. Fluorescent quantitative PCR is more accurate but requires sophisticated equipment and complicated procedures. There is a high false positive rate of ELISA detection methods, and the test of the immunofluorescence antibody takes a long time, and the operation is cumbersome. In recent years, in the field of molecular biology, NanoPCR has become a new type of PCR technique that is more sensitive than traditional PCR. It has been found that NanoPCR thermal cycling can achieve target temperatures faster because of the increased thermal conductivity of gold nanoparticles suspended in the reaction liquid. This faster process of reaching the target temperature helps to enhance reaction specificity and increase product amplification $[15,20]$. The use of nanostructured PCR reaction is a new research direction.

This study shows that our NanoPCR detection is an effective and time-saving BRSV detection method. It saves up to 7-10 min compared to conventional PCR. The sensitivity of the method is ten times higher than that of conventional PCR and this assay is specific to BRSV. Moreover, there is no cross-reactivity to other 


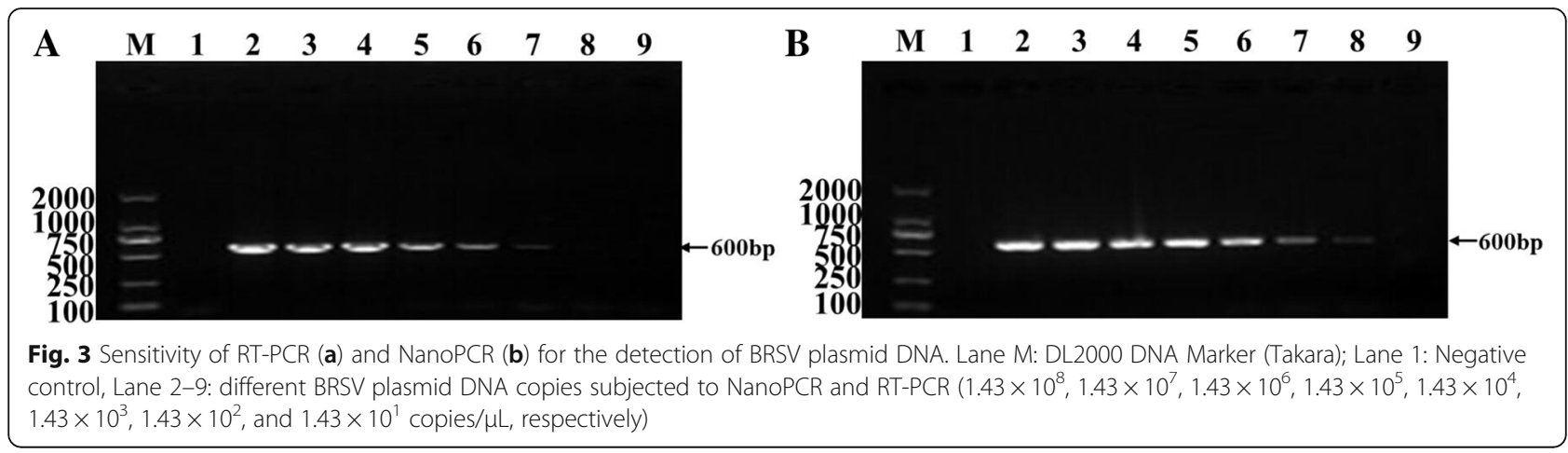

viruses. In summary, we have developed a convenient NanoPCR method for rapid, sensitive and specific detection of BRSV.

\section{Conclusion}

This study we established an efficient, fast, specific, reproducible detection method of BRSV pathogen NanoPCR attributed to the combination of nano-particles in traditional PCR technology. The established BRSV Nano PCR assay can effectively solve the problem of the low titer of BRSV, low detection sensitivity and rate of clinical samples, it also has good specificity and ten times higher sensitivity than conventional PCR, clinical testing efficiency is equally much higher than RT-PCR. Preliminary application based on clinical sample testing. The developed method can be applied to the field of molecular detection of BRSV. It will play an active role in the detection of epidemic diseases, epidemic prevention, purification, and biosafety, to realize the rapid diagnosis of epidemic diseases. It also has essential meanings for both early detections of subclinical infection and disease control.

\section{Methods}

Viruses and clinical samples

The standard positive plasmids (BRSV, BVDV, IBRV, BPIV3) in this study have been described in the previous study [21]. The thirty-nine clinical samples were obtained from different cattle farms in Jilin and Heilongjiang provinces. All samples from our laboratory were saved previously. The samples were taken from the feces and nasal swabs outside the body of the experimental animals, and the whole experiment did not cause harm to the animals.

\section{Viral DNA/RNA extraction}

Extraction of viral RNA from $200 \mu \mathrm{L}$ of pure BRSV culture or tissue samples using E.Z.N.A. ${ }^{\mathrm{nt}}$ Viral RNA Kit (OMEGA Inc., Dusseldorf, Germany) following the manufacturer' instruction. BRSV, BVDV and BPIV3

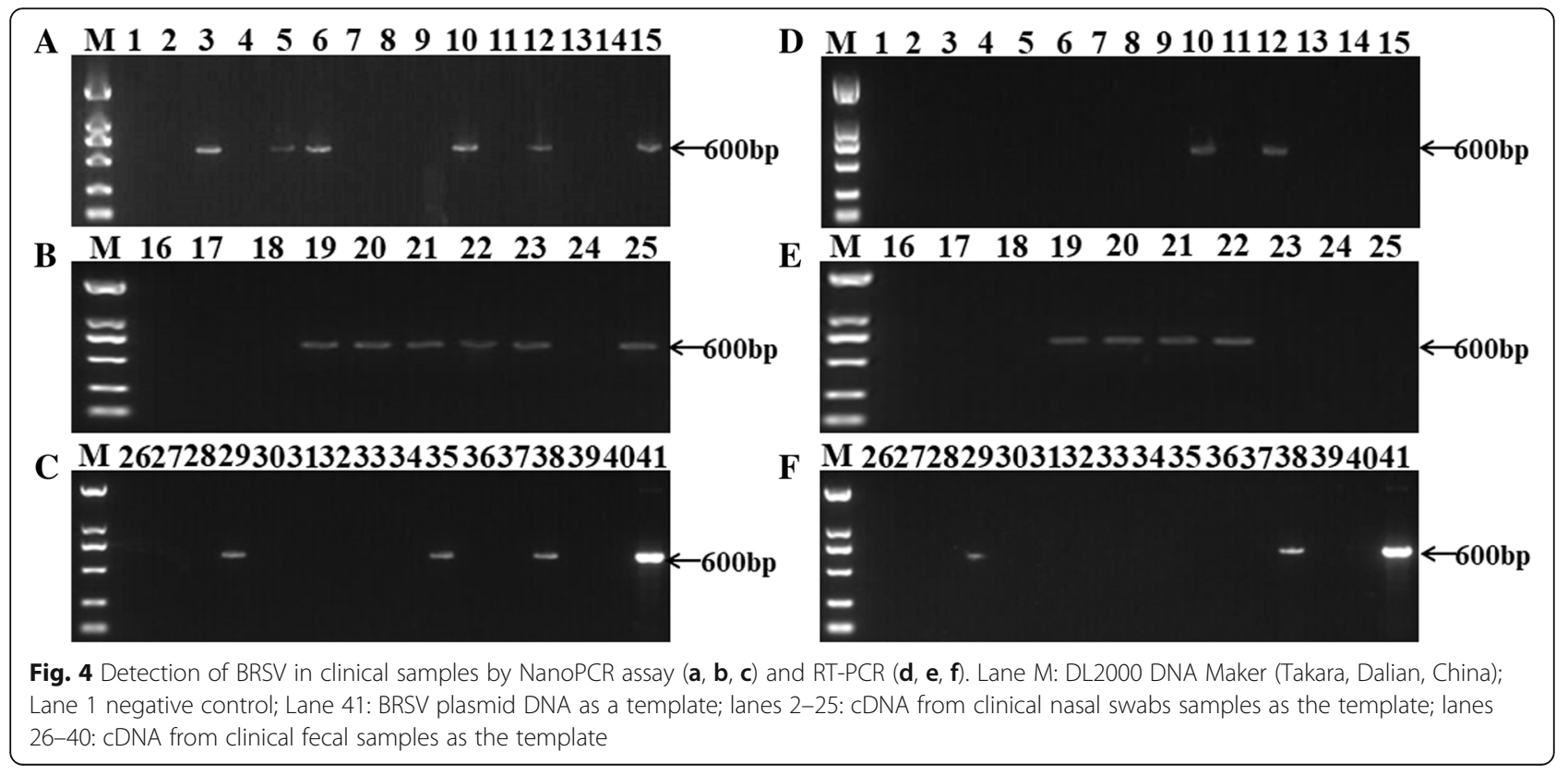


Table 1 NanoPCR and RT-PCR primers used for amplification of BRSV

\begin{tabular}{lllll}
\hline Primer name & Length $(\mathrm{nt})$ & Sequence $\left(5^{\prime}-3^{\prime}\right)$ & Tm $\left({ }^{\circ} \mathrm{C}\right)$ & Product $(\mathrm{bp})$ \\
\hline P1 & 19 & TATGCTATGTCCCGATTGG & 55.4 & 600 \\
P2 & 21 & ACTGATTTGGTAGTACACCC & 58.0 & \\
\hline
\end{tabular}

RNA reverse transcription using reverse transcription kit (TransGen Biotech, AT311-03) following the manufacturer' instruction. The extracts were aliquoted and stored at $-80^{\circ} \mathrm{C}$.

\section{PCR primer}

The common BRSV N gene sequence (GenBank: S40504.1) was obtained by comparing the genomes of different BRSV isolates collected from publicly available sequence data. Primers were selected and designed from conserved $\mathrm{N}$ genes using PRIMER PREMIER 5.0 software (Molecular Biology Insights, Inc., Cascade, CO, USA) to produce $600 \mathrm{bp}$ amplicon (Table 1).

\section{Conventional PCR}

Routine PCR analysis of BRSV was performed using primer group to produce the PCR product with a predicted length of $600 \mathrm{bp}$. PCR was carried out in $25 \mu \mathrm{L}$ reaction volume of $1 \mu \mathrm{L}$ extracted DNA or $0.5 \mu \mathrm{L}$ standard plasmid, $2.5 \mu \mathrm{L} 10 \times$ buffer, $2 \mu \mathrm{L}$ dNTP, $1.5 \mu \mathrm{L} \mathrm{Mg}{ }^{2+}, 0.5 \mu \mathrm{L}$ Taq DNA polymerase (TAKARA), and $0.5 \mu \mathrm{L}$ of each of forward and reverse primer $(10 \mu \mathrm{M})$ by following the manufacturer's protocol with the following cycling times and temperatures: $94{ }^{\circ} \mathrm{C}$ for $5 \mathrm{~min}$ and $35 \mathrm{C}$ cycles of 94 ${ }^{\circ} \mathrm{C}$ for $30 \mathrm{~s}, 57^{\circ} \mathrm{C}$ for $15 \mathrm{~s}$, and $72^{\circ} \mathrm{C}$ for $30 \mathrm{~s}$, with a final extension for $5 \mathrm{~min}$ at $72{ }^{\circ} \mathrm{C}$. PCR was carried out in a Life Express Thermal Cycler (HANGZHOU BIOER TECHNOLOGY CO., LTD, China) and the products were analyzed by $1 \%$ agarose gel [22].

\section{Optimization of BRSV NanoPCR assay conditions}

BSRV NanoPCR optimized the annealing temperature, time, concentration and diameter of gold nanoparticles (SIGMA) with the same primer pairs as conventional PCR. The annealing temperature range of Life Express thermal cycler instrument ranges from $51{ }^{\circ} \mathrm{C}$ to $61{ }^{\circ} \mathrm{C}$. The diameter of gold nanoparticles is $20 \mathrm{~nm}, 23 \mathrm{~nm}$, and $40 \mathrm{~nm}$, the volume range from 0.5 to $1.5 \mu \mathrm{L}$ in increments of $0.2 \mu \mathrm{L}$ by 20 . Products were visualized on $1 \%$ agarose gels at a voltage of $180 \mathrm{~V}$ for $20 \mathrm{~min}$. ImageJ 1.46r software (National Institutes of Health, Bethesda, MA, USA) was used for quantitative gel analysis of all bands.

\section{Specificity of BRSV NanoPCR assay}

The NanoPCR reactions with different viral nucleic acids (including BRSV, BVDV, BPIV3, and IBRV) were performed using optimized reaction parameters to determine the specificity of the NanoPCR assay.

\section{Sensitivity of BRSV NanoPCR assay}

The detection limit of the BRSV NanoPCR assay was compared to the detection limit of conventional PCR using a 10-fold dilution series of BRSV standard positive plasmids (ranging from $1.43 \times 10^{8}$ to $1.43 \times 10^{1}$ copies/ $\mu \mathrm{L})$, and $\mathrm{dd}_{2} \mathrm{O}$ was used as a negative control. The PCR product was electrophoresed on a $1 \%$ agarose gel.

\section{Detection of BRSV in clinical samples}

The thirty-nine clinical samples included feces, and nasal swabs were collected from different cattle farms in Jilin and Heilongjiang provinces. All samples came from our laboratory saved previously. The NanoPCR and conventional PCR assays were performed simultaneously on the thirty-nine clinical samples. Part of the positive samples was sent to sequence by Comate Biosciences Co., Ltd.

\section{Abbreviations}

AuNPs: Au nanoparticles; BPIV3: Bovine parainfluenza virus type 3; BRD: Bovine respiratory disease; BRSV: Bovine respiratory syncytial virus; BVDV: Bovine viral diarrhea virus; CAAS: Chinese Academy of Agricultural Sciences; ELISA: Enzyme-linked immunosorbent assay; IBRV: Infectious bovine rhinotracheitis virus; IHC: Immunohistochemistry; LAMP: Loop-mediated isothermal amplification; PCR: Polymerase chain reaction; RT-PCR: Real-time PCR; SSB: Single-stranded DNA binding protein

\section{Acknowledgments}

Not applicable,

\section{Funding}

National Key R\&D Program of China, No.2016YFD0500900 supported the study. The funding body provided all the help in the design of the study and collection, analysis, and interpretation of data and in writing the manuscript.

\section{Availability of data and materials}

Data sharing does not apply to this article as no datasets were generated or analyzed during the current study.

\section{Authors' contributions}

ZKL and JYL participated in the design of the study, carried out the experiments, analyzed the data and drafted the manuscript. ZYL participated in primers design. JWL and CW helped to process the clinical samples. ZJL and JKW contributed to carrying out PCR. JKW helped to modify the manuscript. LG designed, guided and participated in the experiments. All authors read and approved the final manuscript.

Ethics approval and consent to participate

We had obtained consent from farmers to collect the samples used in my study. We had obtained ethical approval to obtain the samples.

Consent for publication

Not applicable. 


\section{Competing interests}

The authors declare that they have no competing interests.

\section{Publisher's Note}

Springer Nature remains neutral with regard to jurisdictional claims in published maps and institutional affiliations.

\section{Author details}

'Institute of Special Animal and Plant Sciences, Chinese Academy of Agricultural Sciences, Changchun 130112, China. ${ }^{2}$ Graduate School of Northeast Agricultural University, Harbin, China. ${ }^{3}$ Antu Animal Husbandry and Veterinary Station, Yanbian, China. ${ }^{4}$ Graduate School of Jilin Agricultural University, Jilin, China.

Received: 18 August 2018 Accepted: 31 March 2019

Published online: 11 April 2019

\section{References}

1. Van der Poel WH, Brand A, Kramps JA, Van Oirschot JT. Respiratory syncytial virus infections in human beings and in cattle. J Inf Secur. 1994;29(2):215-28.

2. Griffin D, Chengappa MM, Kuszak J, McVey DS. Bacterial pathogens of the bovine respiratory disease complex. Vet Clin North Am Food Anim Pract. 2010;26(2):381-94

3. Larsen LE. Bovine respiratory syncytial virus (BRSV): a review. Acta Vet Scand 2000;41(1):1-24

4. Baker JC, Ellis JA, Clark EG. Bovine respiratory syncytial virus. The Veterinary clinics of North America Food animal practice. 1997;13(3):425-54.

5. Stott EJ, Taylor G. Respiratory syncytial virus. Brief review. Arch Virol. 1985;84(1-2):1-52.

6. Shirvani E, Lotfi M, Kamalzadeh M, Noaman V, Bahriari M, Morovati H, Hatami A. Seroepidemiological study of bovine respiratory viruses (BRSV BoHV-1, PI-3V, BVDV, and BAV-3) in dairy cattle in central region of Iran (Esfahan province). Trop Anim Health Prod. 2012:44(1):191-5.

7. Willoughby K, Thomson K, Maley M, Gilray J, Scholes S, Howie F, Caldow G, Nettleton PF. Development of a real time reverse transcriptase polymerase chain reaction for the detection of bovine respiratory syncytial virus in clinical samples and its comparison with immunohistochemistry and immunofluorescence antibody testing. Vet Microbiol. 2008;126(1-3):264-70.

8. Horwood PF, Mahony TJ. Multiplex real-time RT-PCR detection of three viruses associated with the bovine respiratory disease complex. J Virol Methods. 2011;171(2):360-3.

9. Li H, Huang J, Lv J, An H, Zhang X, Zhang Z, Fan C, Hu J. Nanoparticle PCR: nanogold-assisted PCR with enhanced specificity. Angew Chem Int Ed Engl. 2005:44(32):5100-3.

10. Demming $A$. The state of research after 25 years of nanotechnology. Nanotechnology. 2014, 25(1):010201.

11. Paccaud MF, Jacquier C. A respiratory syncytial virus of bovine origin. Arch Gesamte Virusforsch. 1970;30(4):327-42.

12. Rosenquist $\mathrm{BD}$. Isolation of respiratory syncytial virus from calves with acute respiratory disease. J Infect Dis. 1974;130(2):177-82

13. Smith MH, Frey ML, Dierks RE. Isolation, characterization, and pathogenicity studies of a bovine respiratory syncytial virus. Arch Virol. 1975;47(3):237-47.

14. Brodersen BW. Bovine respiratory syncytial virus. Vet Clin North Am Food Anim Pract. 2010;26(2):323-33.

15. Li M, Lin YC, Wu CC, Liu HS. Enhancing the efficiency of a PCR using gold nanoparticles. Nucleic Acids Res. 2005:33(21):e184.

16. Boxus M, Letellier C, Kerkhofs P. Real time RT-PCR for the detection and quantitation of bovine respiratory syncytial virus. J Virol Methods. 2005:125(2):125-30.

17. Thonur L, Maley M, Gilray J, Crook T, Laming E, Turnbull D, Nath M, Willoughby K. One-step multiplex real time RT-PCR for the detection of bovine respiratory syncytial virus, bovine herpesvirus 1 and bovine parainfluenza virus 3. BMC Vet Res. 2012;8:37.

18. Hazari S, Panda HK, Kar BC, Das BR. Comparative evaluation of indirect and sandwich ELISA for the detection of antibodies to bovine respiratory syncytial virus (BRSV) in dairy cattle. Comp Immunol Microbiol Infect Dis. 2002;25(1):59-68

19. Mayers J, Sawyer J. Development and evaluation of a multiplex enzymelinked immunosorbent assay for the detection of antibodies to bovine respiratory diseases on the Meso scale discovery platform. J Vet Diagn Invest. 2012;24(4):725-9.
20. Ali Z, Jin G, Hu Z, Wang Z, Khan MA, Dai J, Tang Y. A review on NanoPCR: history, mechanism and applications. J Nanosci Nanotechnol. 2018;18(12):8029-46.

21. Guo L, Wang W, Zhang SQ, Sun N, FX Wang HW. Establishment of vaccination test for bovine respiratory disease syndrome-associated virus BVDV, BPIV3, infectious rhinotracheitis virus and BRSV. Specialty Res. 2014;36(01):12-6.

22. Wang J, Cheng $Y$, Zhang M, Zhao H, Lin P, Yi L, Tong M, Cheng S. Development of a nanoparticle-assisted PCR (nanoPCR) assay for detection of mink enteritis virus (MEV) and genetic characterization of the NS1 gene in four Chinese MEV strains. BMC Vet Res. 2015;11(1).

\section{Ready to submit your research? Choose BMC and benefit from:}

- fast, convenient online submission

- thorough peer review by experienced researchers in your field

- rapid publication on acceptance

- support for research data, including large and complex data types

- gold Open Access which fosters wider collaboration and increased citations

- maximum visibility for your research: over $100 \mathrm{M}$ website views per year

At BMC, research is always in progress.

Learn more biomedcentral.com/submissions 